\title{
Formation of structure of high-strength composites with account of interactions between liquid phase and disperse particles
}

\author{
Andrii Plugin ${ }^{1, *}$, Elena Dedeneva ${ }^{2}$, Tatiana Kostyuk $^{2}$, Dmitro Bondarenko ${ }^{2}$, \\ and Olga Demina ${ }^{2}$ \\ ${ }^{1}$ Ukrainian State University of Railway Transport, Building Materials and Structures Department, \\ Feuerbach sq. 7, 61050 Kharkiv, Ukraine \\ ${ }^{2}$ Kharkiv National University of Civil Engineering and Architecture, Building Materials and Products \\ Department, Sumska st. 40, 61002 Kharkiv, Ukraine
}

\begin{abstract}
The ways of composites' directed structuring are covered in this work. The qualitative and quantitative assessment of the role of liquid phase is made. The regime of the effective vibro vacuumizing processof cement composite mixture, which makes it possible to extract free water is developed. Thin-walled articles obtained in this case possess high density, strength with the bend, lowered water absorption and porosity.
\end{abstract}

\section{Introduction}

In the contemporary construction practice the need for thin-walled articles made of finegrained concrete increases. These are the decorative sheets, which imitate natural stone, concrete tile, landscaping architecture of complex configuration, etc.

Improvement of the mechanism of the composite structure formation gives possibility of obtaining the high-quality articles made of fine-grained concrete. It is known that the fine-grained concrete mixtures possess increased waterdemand. Quantity of liquid phase, which ensures the necessary packability of the fine-grained concrete mixture $\mathrm{W}_{\mathrm{lph}}=53-65 \%$ (from the mass of cement) [1]. Quantity of free waterwhich is able to form bug holes, is $\mathrm{W}_{\mathrm{fw}}=34 \%$.

Forobtainingthearticlesofdensestructureandhighstrengththeapplicationofintensivemethod sofconcretemixturepackingwiththepossibilityof free (technological) water removal is required[2]. One of the effective methods from this point of view is vibro vacuumizing [3]. It was established earlier that vibro vacuumizing process gives the possibility to move away from the concrete mixture $29-30 \%$ of water, i.e., all the free liquid [3,4]. The residual water content is more than a quantity of bound water by $4-5 \%$. For the comparison, in the concrete mixtures packed by vibration, the residual water content is $20-23 \%$. Thus, the method appears to be sufficiently effective looking at the quantity of dehydrated water. The study of different vibro vacuumizing regimes gives the possibility of further increase of the structural and physical and physical and mechanical characteristics of thin-walled concrete articles.

\footnotetext{
* Corresponding author: aaplugin@gmail.com
} 
With the formation of concrete structure three phases interact: gaseous, liquid and solid. The liquid phase is water, in which the additional chemical substances which role requires separate examination can be present. From different forms of interactions of liquid and solid phases it is possible to isolate three basic ones. 1) The chemical interaction, caused by hydration and crystallization of the solution of new formations, and formation of the gel of mineral binding. 2) The physicochemical interaction caused by the adsorption of water molecules in the action zone of the surface force field of solid phase. 3) The technological interaction, which makes it possible to lower the viscosity of stock mixture causing the necessary packability of concrete mixture. As it is evident, directed structuring is impossible, first of all, without the qualitative and quantitative assessment of the role of liquid phase.

The goal of the work is obtaining cement composite for the thin-walled articles of the increased density and strength.

For achievement of the stated goal it was necessary to solve the following tasks: to estimate the role of liquid phase in the process of the structuring of cement composite; to develop the effective regime of its packing.

\section{Materials and methods}

Cement composite (fine-grained concrete) in the work was obtained from the following materials. For the laboratory models the Portland cement PC II/A-S-400 (CEM II/A-S-32.5) was used, which corresponds to Ukrainian national standard DSTU B V.2.7-46:2010 requirements "Building materials. Cements of general purpose. Specifications". To achieve high density and waterproofing capacity of concrete, and also more uniform surface of articles, the quartz small sand with the module of the coarseness 1.5 was used. Concrete mixtures of composition $\mathrm{C}: \mathrm{S}=1: 2$ had initial water-cement ratio $\mathrm{W} / \mathrm{C}=0.65$.

For conducting the studies of the influence of different packing regimes on the structural and physical and physical and mechanical properties of fine-grained concrete the models with the size of $350 \times 350 \times 12 \mathrm{~mm}$ were prepared. For determining the strength with the bend within the periods $0,1,3,7,14,28$ of twenty-four hours there were 18 models for each of the regimes. For determining density and water absorption there were 3 models for each regime.

Average density, water absorption and porosity were in accordance with the DSTU B V.2.7-170:2008 requirements "Building materials. Concretes. The methods of determination of average density, moisture, water absorption, porosity and waterproofness".

The determination of strength with the bend of models was conducted in accordance with the DSTU B V. 2.7-43:96 requirements "Heavy concretes. Specifications". The models were experienced on the hydraulic PSU-50 press. The visual inspection of models showed that they do not have cracks. Their structure is uniform.

\section{Theoretical justification for forming high-strength composites structures}

It is known that during mixing concrete ingredients with water their chemical interaction occurs. It is the hydration which means the dissolution of clinker minerals, formation of the supersaturated aqueous solution relative to hydrates, and the formation of hydration products. The part of the water is connected chemically, especially by the crystal hydrates of calcium hydrosulfoaluminates (CHSA). A quantity of water, connected by CHSA, gradually increases from $1-2 \%$ during the first minutes of their formation to $13 \%$ toward the end the gripping. 
Together with the chemical one the physicochemical interaction occurs, which includes a change in the polar properties of water molecule (Fig. 1). Falling into the power surface field of solid phase, which can have electro-surface potential ( 0 and electro-kinetic $\xi$ potential surface different in sign and value (for example, $\mathrm{SiO}_{2}$ is negative, $\mathrm{Ca}(\mathrm{OH})_{2}, \mathrm{CaO}$, CHSA is positive), the water dipoles are attracted to the active centers by pole with the opposite sign $[1,5]$.
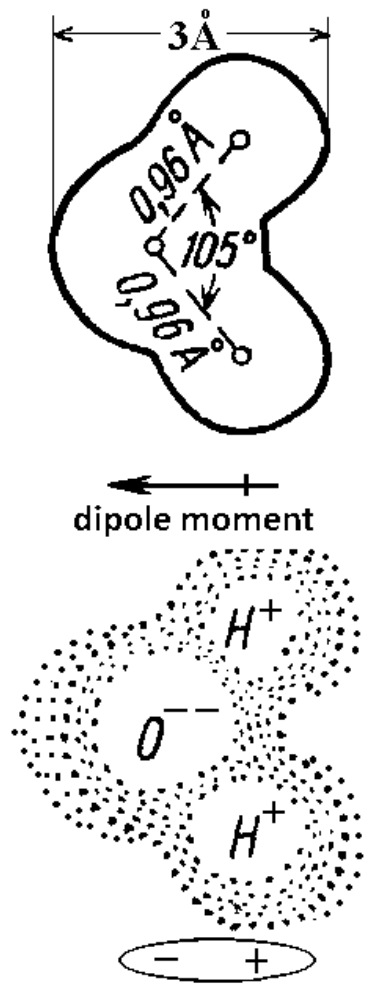

Fig.1. Change in the configuration of water molecule with change in the dipole moment.

On the rigid surface they form a film in the form of the salvation sheath, which consists of several adsorptive and diffusion layers. The thickness of films depends on mineralogical composition and mass of the particles of solid phase.

With its properties the adsorbed water approaches a pseudocrystalline body with the density 1.2-2.0 of g/ $\mathrm{cm}^{3}$, the significant elasticity, the strength with the shift at about $1 \times 10^{4}$ $\mathrm{Pa}$, the low freezing point being lower than $195 \mathrm{~K}$ [3]. Such anomalous boundary layers of water depend on the presence of the dual electrical layer (DEL) on the border of the division of solid and liquid phases.

DEL is formed in the thin capillaries on the surfaces of colloidal and highly dispersed particles due to the adsorption of ions from the solution on the rigid surface. As a result of interaction with the solution the colloidal new formation micelle appears, in which the solid phase (nucleus) is connected with the solution through stabilizing DEL, and sometimes it happens through the salvation sheath (Fig. 2a, b).

On the border of adsorptive and diffuse DEL zones $\xi$-potential appears during the motion of liquid relative to the surface of the nucleus of micelle, (Fig. 2b), which characterizes the intensity of electro-kinetic phenomena and corresponding physical chemistry processes, which lead to the appearance of the crystal hydrate structure of the concrete block [3]. 


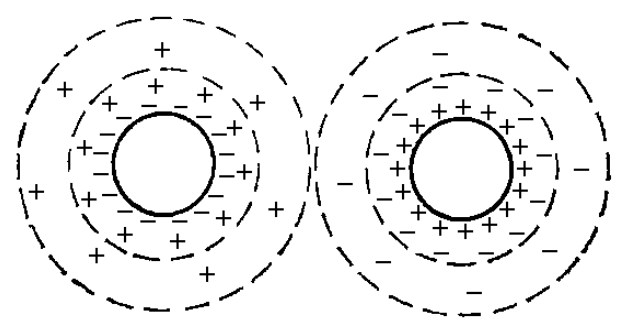

(a)

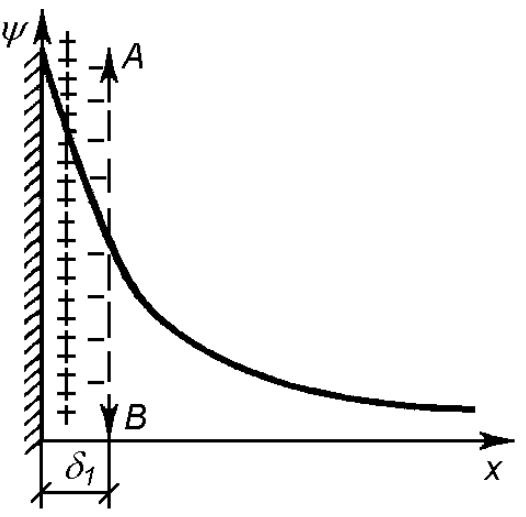

(c)

Fig.2. Forms of connection and the value of $\psi$ potential on the division border of "solid phaseliquid": (a) with the negatively charged particle; (b) with the positively charged particle; (c) charge and potential distribution in the micelle.

The structural strength of concrete to a considerable extent depends on the electrosurface properties of the components [5-7, 9-12]. During the first minutes the positively charged particles of CHSA of colloidal sizes are actively formed in the freshly prepared concrete mixture. $\mathrm{SiO}_{2}$ sand particles are minus charged. Since the hydrogenous bonds are oriented equally probably in all directions in the volumetric free water, and strengthening the dipole in parallel oriented moments the excessive orientation of hydrogenous bonds in the direction of the surface of solid phase appears in the boundary layer, the orienting action of electrical surface field is strengthened. This causes the appearance of durable electro-heterogeneous contacts between the particles of cement and sand (Fig. 3). Water demand for hydrosilicate gel is $\mathrm{K}_{\mathrm{g}}=0.18 \mathrm{C}$.

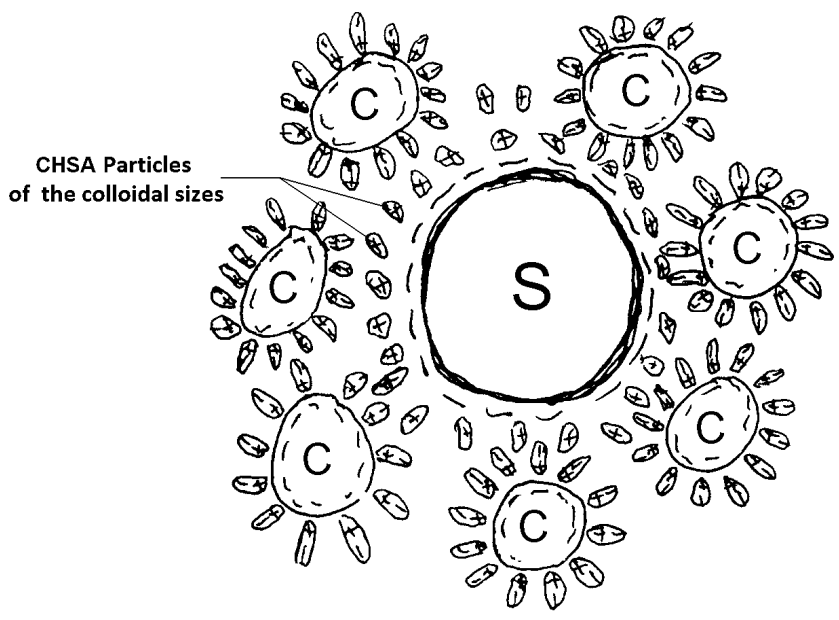

Fig. 3. Scheme of the formation of electroheterogeneous contacts between the particles of cement and sand in the initial period of the formation of fine-grained concrete structure

The water, which did not enter the crystal-hydrates, is structured having different effect on the physical and mechanical properties of concrete block and after that of concrete and solution.

A quantity of physically bound water depends on the summary specific area of the particles of solid phase, i.e., the granulometric composition of the fillers of concrete 
mixture. For the fine-grained concrete mixtures a quantity of physically bound water is more than for the concretes on the coarse filler. The role of the structured liquid phase especially grows for the fine-grained concretes, the water demand for fine sands is $\mathrm{K}_{\mathrm{s}}=$ 0.12 and for coarse sands is $\mathrm{K}_{\mathrm{s}}=0.08$ [1].

With respect to the value of the specific surface area of filler a quantity of physico chemical bound water for the concrete mixture varies in the limits of $\mathrm{K}_{\mathrm{ph}-\mathrm{ch}}=0.26-0.30$. Technological interaction between the liquid and solid phases is specified by the need of guaranteeing the packability of concrete mixture, which to a considerable degree depends on the raw-material base of fillers. Taking into account that at the present time most regions have got fine-grained sands, the industry of building materials must use the technologies, which give the possibility to obtain concretes of dense structure on the fine and very fine sands.

Due to the fact that physicochemical bound water near the solid surface has the special properties similar in the indices to the properties of solid body, it is necessary to insert the physically free liquid for guaranteeing the packability of concrete mixture on the fine fillers Its quantity can be determined according to the value of the specific area of the particle of solid phase (table 1). The indirect index, which considers the composition of cement and its physical properties, is the normal thickness of the cement test $\mathrm{K}_{\mathrm{n} \text {.th }}$.

Table 1. Dependence of thickness and volume of solvate film on the grains of quartz sand on average size of its particles and their specific surface area

\begin{tabular}{|c|c|c|c|}
\hline $\begin{array}{c}\text { Average size of } \\
\text { quartz sand grains } \\
\mathrm{D}_{\mathrm{av}}, \mathrm{mm}\end{array}$ & $\begin{array}{c}\text { The specific surface } \\
\text { area of quartz sand } \\
\text { grains } \mathrm{S}_{\mathrm{s}}, \mathrm{sm}^{2} / \mathrm{g}\end{array}$ & $\begin{array}{c}\text { Thickness of } \\
\text { solvate film, } \\
\mathrm{d}_{\text {s.f. }} \mu \mathrm{m}\end{array}$ & $\begin{array}{c}\text { Volume of } \\
\text { solvate film, } \\
\mathrm{V}_{\text {s.f. }}, \mathrm{sm}^{3}\end{array}$ \\
\hline 1.60 & 18.5 & 4.1 & 0.07585 \\
\hline 0.90 & 33.0 & 4.0 & 0.13200 \\
\hline 0.63 & 52.8 & 4.0 & 0.21120 \\
\hline 0.45 & 66.0 & 4.0 & 0.26400 \\
\hline 0.23 & 129.0 & 3.9 & 0.50310 \\
\hline
\end{tabular}

In the opinion of I.N. Akhverdov [8] taking into account the recommendations of V.S. Fadeeva molding humidity and necessary quantity of liquid phase must exceed $\mathrm{K}_{\mathrm{n} \text {.th }}$, also, in the technology of concretes with the contemporary methods of packing (vibration, centrifugation) on the average comprises:

$$
\mathrm{K}_{1 . \mathrm{ph}}=1.65 \mathrm{~K}_{\mathrm{n} . \mathrm{th}} .
$$

where 1.65 is the coefficient, depending on the specific area of the particles of solid phase with their average coarseness.

In the dependence (1) possible deviations in the compositions of concretes are not considered, in particular, the granulometry of fine filler. On the basis of the analysis of the experimental data about the water-requirement for concrete mixtures on the fine-grained fillers, sands of different coarseness, [1, 4, 10-12] the coefficient value, which considers the increased water-need of fine sands, is obtained. Dependence (1) for the fine-grained concretes on the fine sands takes the form:

$$
\mathrm{K}_{1 . \mathrm{ph}}=1.98 \mathrm{~K}_{\text {n.th. }} \text {. }
$$

For example, for the fine-grained concrete on PC II/A-S-400 cement with $\mathrm{K}_{\text {n.th }}=0.27$ the total quantity of liquid phase, necessary for the preparation of the fine-grained concrete mixture with $\mathrm{K}_{1 . \mathrm{ph}}=1.98 \times 0.27=0.53$ (taking into account technological interactions we assume $\left.\mathrm{K}_{\mathrm{l} . \mathrm{ph}}=0.60\right) ; \mathrm{K}_{\mathrm{cr}}=0.01$ enters into crystal-hydrates; it is physic-chemically 
connected in the salvation sheaths $-\mathrm{K}_{\mathrm{ph}-\mathrm{ch}}=0.30$. Then a quantity of free water, capable to form the bug holes during the evaporation is $\mathrm{K}_{\mathrm{fr}}=0.60-0.01-0.30=0.29$.

With the introduced quantity of liquid phase for obtaining the concrete of dense structure it is necessary to develop the effective regime of vibro air free process, which provides the total removal of free water.

It is known $[2,4]$ that molding articles made of fine-grained concretes is divided into two stages: 1) the vibratory compaction of concrete mixture packed in the form during $10 \mathrm{~s}$; 2) the vacuum processing of the provibrated concrete mixture with the negative pressure $0.07 \mathrm{MPa}$ during $10 \mathrm{~s}$.

In view of the fact that liquid with this regime is moved away from the condensed concrete mixture, in the space, earlier occupied by water, the directed capillaries, by microand ultra micro pores are formed. It is difficult to assume how they subsequently will be filled up with the products of new formations. For obtaining a maximally dense concrete structure it is necessary to bring a quantity of free water moved away from the mixture to $34 \%$, and to also ensure liquidation of the directed capillaries. Repeated short-term vibration must be effective additional technological operation for this, it is desirable with tightening weight.

\section{Research results and their discussion}

Studies regarding the stages of the technological regimes of packing for the structural and physical and physico-mechanical properties of the fine-grained concretes have been carried out. Three series of the technological regimes of packing have been accepted: I - control room is the vibratory compaction of concrete mixture during $10 \mathrm{~s}$; II - vibratory compaction during $10 \mathrm{~s}$ with the subsequent air free process during $9 \mathrm{~s}$; III - vibratory compaction during $10 \mathrm{~s}$ with the subsequent air free process during $9 \mathrm{~s}$ and the repeated vibration during $10 \mathrm{~s}$ with tightening weight of $5 \mathrm{~kg} / \mathrm{sm}^{2}$.

The duration of vibration and air free process are assigned employing the procedure [4]. Models hardened under the normal hydrothermal conditions in the course of 28 days.

The influence of the regimes of concrete mix compaction on the bending strength of concrete $R_{b}$ is illustrated by the graph, represented in Fig. 4

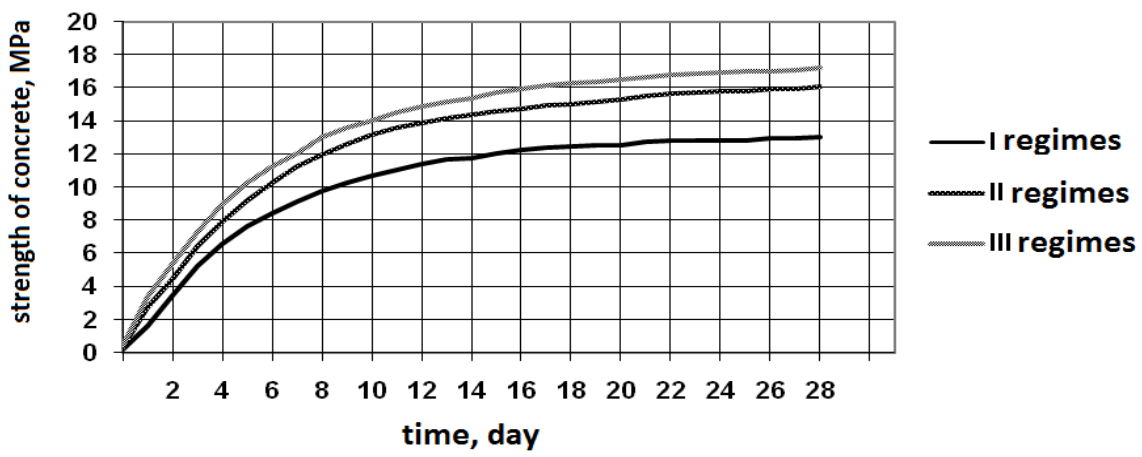

Fig. 4. The influence of the compaction regimes on the strength of concrete.

It is evident from the graph that the best regime for the extraction of free water during packing of thin-walled articles is the regime III. It combines vibratory compaction, vacuumizing with the subsequent vibratory compaction of mixture with tightening weight. This technological solution contributes to the destruction of the directed capillary holes formed in the air free process. As a result, the structure of cement composite is packed 
which contributes to an increase in strength (Fig. 4) and in the waterproofing of thin-walled articles made of the cement composites.

In the course of experiment, a quantity of water extracted from the mixture was controlled, as well as density, porosity, water absorption and strength of concrete. Results are given in the table 2 .

Table 2. The structural and physical and physic-mechanical indices of fine-grained concretes with different technological regimes of the packing

\begin{tabular}{|c|c|c|c|c|c|c|c|c|c|c|}
\hline \multirow{3}{*}{ 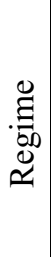 } & \multirow{3}{*}{$\begin{array}{c}\text { Quantity } \\
\text { of water } \\
\text { extracted } \\
\text { from the } \\
\text { mixture, } \\
\%\end{array}$} & \multirow[b]{3}{*}{$\begin{array}{c}\text { Density, } \\
\mathrm{kg} / \mathrm{m}^{3}\end{array}$} & \multirow{3}{*}{$\begin{array}{c}\text { Water } \\
\text { absorptio } \\
\text { n, } \%\end{array}$} & \multirow[b]{3}{*}{$\begin{array}{c}\text { Porosit } \\
\mathrm{y}, \%\end{array}$} & \multicolumn{6}{|c|}{ Bending strength $\mathrm{R}_{\mathrm{b}}, \mathrm{MPa}$, at the age of: } \\
\hline & & & & & \multirow[b]{2}{*}{$\begin{array}{c}1 \\
\text { hour }\end{array}$} & \multicolumn{5}{|c|}{ days } \\
\hline & & & & & & 1 & 3 & 7 & 14 & 28 \\
\hline $\mathrm{I}$ & - & 2355 & 6 & 11.0 & 0.20 & 1.60 & 5.20 & 9.10 & 11.70 & 13.00 \\
\hline II & 29.3 & 2430 & 5 & 10.1 & 0.36 & 2.75 & 6.44 & 11.27 & 14.40 & 16.10 \\
\hline III & 33.6 & 2500 & 3 & 7.2 & 0.42 & 3.35 & 7.30 & 12.04 & 15.35 & 17.20 \\
\hline
\end{tabular}

\section{Conclusions}

It was determined, that for obtaining the required mobility of mixtures a quantity of water in the volume sufficient for creating the layers, removed from the action of the potential of rigid surface is necessary. As a result of studies the obtained value of the coefficient, which considers the increased water demand of small fractions, has given the opportunity to determine the total quantity of liquid phase necessary for the preparation of the fine-grained cement mixture $-\mathrm{K}_{1 . \mathrm{ph}}=0.6$ (from the cement), and also a quantity of free water, capable during the evaporation to form the bug holes $-\mathrm{K}_{\mathrm{fr}}=0.29$ (from the cement).

For obtaining the cement composites with the high density it is necessary to provide the conditions of creating thin structured layers of the liquid between the particles of the solid phase of mixture. It is determined, that the most rational method of the extraction of free water is the air free process.

Experimental studies established that the developed technological regime III (vibratory compaction during $10 \mathrm{~s}$ with the subsequent air free process during $9 \mathrm{~s}$ and the repeated vibration with tightening weight of $5 \mathrm{~kg} / \mathrm{cm}^{2}$ during $10 \mathrm{~s}$ ) ensures the complete removal of the free liquid phase from the packed mixture.

Fine-grained vacuum concrete, packed under the developed regime, has the increased structural and physical and physical and mechanical characteristics in comparison with the concrete packed by vibration. Thus, increase in concrete density comprises $6 \%$; reduction in water absorption $-52 \%$, of the porosity $-65 \%$. The structural strength of concrete increases 2 times and composes $0.42 \mathrm{MPa}$, which gives the possibility to achieve the immediate removal of the molds of articles. The strength of concrete at the age of 28 twenty-four hours increases by $32 \%$.

\section{References}

1. Yu.M. Bazhenov, Vysokoprochnyy melkozernistyy beton dlya armotsementnykh konstruktsiy (Gosstroyizdat, Moscow, 1963).

2. A.G. Vandolovskiy, Ye.B. Dedeneva, Naukoviy visnik budivnitstva, 41, 127-132 (2007)

3. A.G.. Vandolovskiy, Ye.B. Dedeneva, Naukoviy visnik budivnitstva, 47, 192-195 (2008) 
4. V.S. Babushkin, Ye.B. Dedeneva, Ye.V. Yemets, D.A. Bondarenko, Naukoviy visnik budivnitstva, 31, 123-127 (2005)

5. A.N. Plugin, A.A. Plugin, Collected scientific works of Ukrainian State University of Railway Transport, 77, 5-70 (2006)

6. A.N.Plugin, A.A.Plugin, O.A.Pluhin, A.S.Kaganovskii, O.V.Gradoboev, 18 Ibausil, Weimar, 1, 0656-0663 (2012)

7. A.N.Plugin, A.A.Plugin, O.A. Kalinin et al. Osnovy teorii tverdeniya, prochnosti, razrusheniya $i$ dolgo-vechnosti portlandtsementa, betona $i$ konstruktsiy iz nikh (Naukova dumka, Kyiv, 2012)

8. I.N. Akhverdov, Osnovy fiziki betona (Stroyizdat, Moscow, 1981)

9. A.N. Plugin, Elektrogeterogennyye vzaimodeystviya pri tverdenii tsementnykh vyazhushchikh, DSc(Chem) thesis (Dumanskiy Colloid Chemical and Water Chemical Instite of NAS of Ukraine, Kyiv, 1989)

10. A.N. Plugin, A.A. Plugin, O.A. Kalinin, Cement, 2, 28-32 (1997)

11. A.A.Plugin, T.A.Kostyuk, M.G.Saliya, D.A.Bondarenko, Sbornik nauchnykh trudov MGSU posvyashchennyy 90-letiyu fakulteta PGS, 224-227 (2011)

12. A.A.Plugin, M.G.Saliya, T.A.Kostyuk, D.A.Bondarenko, O.V.Starkova. VIII Mezhdunarodna nauchno-prakticheska konferentsia «Nauchnoye prostranstvo Yevropy», 29, 62-67 (2012) 